\title{
Introduction \\ The Form of History and the History of Form
}

A GOOD PART of American literature may be characterized as autobiographical, and while this study is not a survey of American autobiography, it is to a certain extent an examination of autobiographical literature in America. In choosing to consider Henry David Thoreau's Walden, Walt Whitman's "Song of Myself," Henry James's Prefaces, Henry Adams's The Education of Henry Adams, William Carlos Williams's Paterson, and the poetry of Frank O'Hara, I have tried both to represent the variety of autobiographical literature and to indicate a corresponding variety of approaches to it. As my choice of examples suggests, the term "autobiographical" here does not imply any particular standard of "truth" to the "facts," since the recording of a life necessarily represents the fictionalization - to a greater or lesser degree - of the life lived. In my usage, "autobiographical" refers to works in which the hero, narrator, and author can be identified by the same name. I am not interested so much in the motivations of strictly autobiographical recordings as in the structures and dynamics of writers' creating literature out of their historical selves.

This interest has led me to choose Walden and "Song of Myself" as my starting points. Yet the predominance of the autobiographical mode in American literature suggests that this subject is in some way distinctively American, and the works that I study are related to earlier manifestations of the autobiographical impulse in Puritan spiritual autobiographies, on the one hand, and in Benjamin Franklin's story of his archetypal worldly progress, on the other. As various readers have pointed out, a work like Waldenwith its innerness and all-consuming self-consciousnesscan be traced back to a work like Jonathan Edwards's 
Personal Narrative. But this is not all of Walden: the Thoreau persona is also a shrewd, calculating Yankee, who is closer to a Ben Franklin than to an Edwards. "Song of Myself" has likewise been placed in the tradition of Puritan and Quaker spiritual autobiographies. Yet "Song of Myself" is also an expression of an extremely fluid environment and the archetypal chameleonlike hero that this environment inspires - a process first enacted and recorded by Franklin's elusive hero.

The range of such possible connections suggests that in tracing a tradition of personal literature in America one is dealing less with direct influences and more with a series of responses to essentially similar social, spiritual, and literary experiences. For example, the enduring fluidity of the American environment fosters a kind of isolation that makes the writer turn inward and explore, as Thoreau puts it, "the Atlantic and Pacific Ocean of one's being alone." At the same time, the writer's relation to the reader has to become more or less didactic, as the inner experiencesometimes its very inwardness itself-becomes a public example in being communicated. In this way, autobiography has proved to be a congenial form for American writers, because it asserts both their spiritual power to create or regenerate themselves and their potentially political power to change hearts and minds. The two strains of American autobiography-the spiritual or religious and the worldly or political - come together in Thoreau and Whitman, who offer us simultaneously spiritual instruction and worldly lessons in survival. The two kinds of instruction are inseparable in Thoreau and Whitman because their exemplary personal experiences were not their sole way of communicating some truth that transcended the history of the self. Instead, the self - the "simple separate person"- and its history and communication had become their literary subject, their American material. Unlike Edwards or Franklin, then, Thoreau and Whitman were primarily artists and saw themselves as such.

I have chosen to begin this study with the first examples 
of autobiographical literature that we have, for my purpose is not to provide a definitive theory of autobiography in America but to define the critical approaches that autobiographical literature demands. Indeed, my primary purpose is to develop a method of talking about literature as a totality - a method that would render terms like "subject," "form," and "style" exactly convertible to each other. Autobiographical literature is particularly suited to my purpose, for it reveals the dynamics of its creation more readily than other kinds of literature and thereby gives us a chance to observe the literary work as the whole that it is at its inception. I intend, then, to explore the process of creationthe process by which history becomes conscious and consciousness becomes form. And autobiography actually enacts the conversion of history into form not just once but continuously, because the "I" in its self-consciousness constitutes at the same time the historical subject, the shaping form, and the personalizing style of autobiography.

Thus autobiographical literature has the status of a metaliterature, because it reveals the process by which history and form become convertible. As literature, such a work embodies a dialog with its tradition and modelswith the history of its form and language. For example, The Education of Henry Adams is deliberately cast as a conscious dialog with its tradition, for it represents a completion of Saint Augustine's Confessions, a rebuttal of the Confessions of Jean Jacques Rousseau, and an inversion of The Autobiography of Benjamin Franklin. Moreover, part of the significance of works like Walden, "Song of Myself," and Paterson derives from their experimental forms, which embody their respective dialogs with English and American literary tradition. Even an apparently unprecedented undertaking like James's Prefaces may be seen in the context of such models as Dante's La Vita Nuova, Poe's "The Philosophy of Composition," and Hawthorne's and Melville's various prefaces, for any literary work exists as a dialog with tradition, whether this dialog is consciously articulated or not. 
We could say that the history of literature represents a continual self-transcendence-a continual surpassing of what has become convention. ${ }^{1}$ Yet the momentum of form alone cannot explain the departures from tradition that make for art. The fact that a particular departure or transformation becomes conceivable, possible, or necessary at a given time attests to the artist's involvement in another dialog, which is extraformal and has its own momentum. This second dialog is with history or with the artist's temporal experience in the context of his or her perception of the total collective experience. As such, the artist's history includes his or her consciousness or the very appropriation and transcendence of history; as a result, we could even speak of an antiformal dialog and regard the work as a clash between the conservatism of form and the radical nature of consciousness, which exists as continuous change and self-transcendence. The literary work, then, may be seen either as form informing history or as history transforming form.

Autobiography records this transaction while enacting it. To begin with, the subject of autobiographical writing is the self becoming conscious of itself in and as history. Although this statement most obviously characterizes Paterson and O'Hara's poems, it applies equally to the most closed work under consideration. The Prefaces of Henry James also constitute a transformation of the private self into a public hero, since the simple act of self-consciousness itself involves the recognition of oneself as representative and, therefore, as functioning in and as history. After all, recognition of one's identity as consciousness attests to one's identity with all conscious beings. Second, the inclusive form of autobiography embodies the interaction of history and consciousness. The "I" becomes the organizing principle, for it is in being perceived by the " $\mathrm{I}$ " that diverse phenomena become related. Moreover, the "I" provides not only the formal center but the very form of the work. For example, the cyclical progression of Walden, the self-transcending evolution of "Song of Myself," the self-destructive 
degeneration of The Education of Henry Adams, and the "dissipation" of Paterson are formal patterns that reflect exactly the personal needs of their respective authors. Finally, style is not only self-expressive but has a historical function as well: as O'Hara's career demonstrates most dramatically, it is style that makes the "I" an "I"- a continuous, publicly enduring entity. Thus, although subject, form, and style in autobiography are so many mirrors reflecting each other, it is also true that autobiography transcends this solipsism, for not only has the self-recording consciousness developed within a particular historical context, but the formal patterns and the style that shape and reshape this development, as well as the narrative and the language that record it, are modes of organization and communication that are shared by the culture as a whole. Autobiography, then, represents a self-examination that is at the same time private and public, for the interaction of personality and collective life that autobiography embodies is reflected in the author's personal appropriation of the language of the times. Since autobiography thus bridges public and private life, the hero of autobiography is the paradoxical private-person-as-public-hero. As we shall see, it is in being communicated or in being made public that introspection - the inner ordeal-becomes heroic. Therefore, just as history becomes conscious and achieves form in autobiography, consciousness itself becomes history in achieving form.

Since the subject and form of autobiography meet in the historical experience of its author-hero, the genre naturally remains quite protean. As the variety of my examples illustrates, the forms of its expression are created by each writer out of personal needs. Thus autobiographical literature is particularly suitable for a study of the interaction of history and form, because it is this kind of literature that retains the closest ties to its roots as a space-time event. If a literary work is seen as an event, history and literature, content and form, and public language and style become useless distinctions. Maurice Merleau-Ponty complains that 
the Museum detaches works of art from the chance circumstances of their creation and leads us to believe that the artist's hand was guided from the start by fate: "the Museum converts this secret, modest, non-deliberated, involuntary, and, in short, living historicity [of the creation] into official and pompous history."2 Similarly, Jean-Paul Sartre accuses the Library of making "messages" of what were originally gestures. This kind of transformation, which alienates the work from its historicity and its life as an event and makes of it a "relic," parallels the dissection of the work into form, content, language, and style. Yet Merleau-Ponty's statement needs to be qualified. If we approach the completed work as we approach any past event, the work will be seen to consist of both freedom and fate. Only within the context of fate can the past be retrieved as the set of possibilities that it was, not simply because it has already become an undeniable present but because only the present - the fate of the past - can provide a clue to the range of past possibilities. Thus the completed form may be seen as the fate of the work's historicity. Just as autobiography records the conversion of history into form, as literature it also embodies this conversion in reverse, since its form is necessarily historical. As a result, autobiography bridges art and history and represents a denial both of art as an absolute activity and of history as metaphor and meaning. Art and history are thereby personalized, and the experience of time is reintroduced as the center of each. Thus I am interested in finding an approach that would relate writers as persons in history to their art and, at the same time, would stay clear of psychological and historical interpretations alike. While the psychological emphasis discounts the public history and the function of art as rhetoric, the historian's approach subordinates the private history and the private problems that the work creates as well as solves. Moreover, both of these approaches minimize the momentum of form or the dialog with its tradition that the work embodies; an ideal approach would attempt to comprehend this dialog also. 
Seen as event, literature reverts to drama or, more accurately, to ritual. In autobiographical literature as ritual, the artist may be seen to enter into formal communication both with the age or history and with the past, which includes literary tradition as well as one's personal past. As each of the works under consideration demonstrates, autobiography provides one with a way of placing oneself in history. If we regard literature as formal communication, however, we can no more use it to learn about its age than we can account for its forms with our knowledge of the period, since as a ritual experience the literary work exists as the confluence of public and private significances. The work represents the point at which a particular relation between the self and the collective experience can be marked in - and preserved from - time, for the time structure that a literary work creates makes a niche in time and marks a point or moment, much as a cathedral makes its mark not only in the space of art history but in geographical or real space. Similarly, the point that the literary work marks in historical time is essentially nonrepeatable, but the point that it marks in physical time is repeatable even now, because physical time is always present. As in ritual, then, the originating context and experience are essentially nonrepeatable, because they arise from a subjective appreciation of a particular moment in time. As form, however, the literary experience is eminently repeatable, because the work is equally accessible to all users of its language. When the literary work is seen as formal communication, even content becomes form - that is, it becomes a locus of events and ceases being particular and unique. It is for this reason that a single form is able to accommodate diverse experiences or events. When seen as history, each experience is unique; when seen as form, it becomes similar to a whole class of experiences. As a result, literature requires very few forms in order to make a limited number of statements again and again. Yet each form is always discovered anew, because each statement is always arrived at personally out of each writer's needs. 
When we regard literature as a ritual event, we can reconcile the idea of art as a response to a specific historical -psychological and public-context or as a "strategy for living"3 and the idea of art as drama or as a purely formal conversion of private time into history. As ritual event or, more simply, as gesture, the work has a historical context but a repeated and repeatable form. Susanne Langer sees ritual as originating in "gestures," which are "natural actions" transformed into formal actions through self-conscious repetition. Similarly, we could say that in being transformed into art the artist's acts become gestures. As such, the artist's acts become deliberate, for they are no longer, in Langer's terms, "emotional acts" that are "subject to spontaneous variation"; instead, they are "bound to an often meticulously exact repetition, which gradually makes their forms as familiar as words or tunes." 4 Thus the artist's act is transformed from emotional expression into pure drama and thereby becomes our ritual. Although the experience in drama is formally and objectively defined and delimited, its reenactment, which represents its fulfillment, is necessarily an experience in the history of the reader, and its significance, therefore, is necessarily subjective.

In this way, art comes to transform history, which is the avowed enemy, so to speak, of anyone who writes autobiography. And history ranges from being simply unreal in the experience of Thoreau and Whitman to being a nightmare in the extreme experience of Adams. Unreal and chaotic, history is a dream, for in its essence it escapes the mind's grasp - that is, in its essence it is unrepeatable. Only temporal phenomena that repeat themselves and thus coincide with biological time can be appropriated as myth. History becomes myth only upon being abstracted into repeatable messages, and since repetition itself is cohesive, history-as-myth makes for cultural cohesion. This transformation of history into myth constitutes the basis of cultural identity in America, and Whitman's poetry, for example, is partly a response to and partly responsible for this 
mythicizing of history. Autobiographical literature represents one more attempt to make the unrepeatable repeatable or, in other words, to make the uniqueness of history partake of the recurrence of myth.

As literature, then, the autobiographical work is dramatic in its repeatable form; as semihistorical recording, however, it is a strategy for living, for its subject is the repetition of one's life. D. H. Lawrence writes that "one sheds one's sickness in books - repeats and presents again one's emotions, to be master of them."' Yet repetition is curative in a more basic way. By reliving the passively suffered dream of history, one makes it real and comprehensible, since repeating one's history is a way of mastering it. For this reason, Freud regards repetition compulsion as stronger than even the pleasure principle; however painful the experience that one once suffered passively, one is compelled to relive it over and over in order to master the situation." This compulsion, which may be seen, say, in children's playing doctors or teachers and thereby actively mastering unpleasant situations, informs the autobiographical impulse as well. For example, Whitman's catalogs represent his attempts to come to terms with the disorder and the discrepancies in what he perceives, for the catalogs retain something of the chaotic element that initially made his experience less than totally pleasurable. Similarly, twentieth-century urban poets like Williams and O'Hara also repeat in their work what most resists mastery-the chaos, violence, and speed of city life. Moreover, from Thoreau's re-cycling of nature in his Journal and Walden to James's minute re-visionings and Adams's reconstruction of his career, this mastery through repetition is the object of autobiographical writing. When the particulars or facts of history form a system of relations in a work of art, they become repeatable and therefore constitute a comprehensible experience. On the other hand, old newspapers, for example, are unreadable and essentially incomprehensible, because the particulars remain too close to their roots in the chaos of history. 
The relations that autobiography establishes do not necessarily derive from an external system or theory that is imposed on experience; instead, the life simply is this particular configuration of these particulars. Thus the relations between experiences are historical or temporal relations, and temporality organizes as well as informs the experience in autobiography. For autobiography is not a static meditation on the self. As Roy Pascal argues, the self is so elusive that it can be grasped only through a historical narrative, not analytically. ${ }^{7}$ Although Whitman, for example, rejects narrative in favor of an evolutionary progression, even he employs a historical or temporally irreversible order in shaping his history. The relations, then, are those of the telling; or since the telling, the style, the form, and the person are one in autobiography, the relations are those that personality establishes, and particulars that are related to a personality are related to each other. Since the repetition is formal, however, and since the relations are established in language, they are not private relations. Not only does their significance become public, but they are public at their very inception, for language and the structures of narrative embody connections and patterns of relation that are shared by the entire culture.

In making history repeatable, art denies time. Like science and the writing of history, art is a ruse for escaping history, because it works with repeatable time. As a result, the novel is, in Roland Barthes's words, "a Death; it transforms life into destiny, a memory into a useful act, duration into an orientated and meaningful time." 8 This statement, which O'Hara's "In Memory of My Feelings" corroborates for poetry, applies equally to autobiography, which in the hands of Thoreau and Adams actually becomes an anticipation of death. As repetition-in-reverse, however, anticipation represents another strategy for gaining control over history. For instance, Whitman masters the future by anticipating in the 1855 "Song of Myself" the very person he was to become. Similarly, when James recollects his career in the Prefaces and sees himself as anticipating all 
along the artist that he has become, he is mastering his past. Autobiography, then, is repetition: either it repeats life, as, say, in the case of Adams, or life repeats it, as in the case of Whitman. Better yet, as Thoreau, James, and Williams illustrate, both processes go on simultaneously.

The principle of repetition also informs the peculiar economy or essential narcissism of autobiography. Beginning with the Romantic period, poets see their authority diminish and their range of subjects shrink to the extent that, eventually, they can speak only about themselves. When one casts oneself as the center of reality, however, one becomes committed to continuous self-scrutiny. For the "phantom of life" that the poet seeks resides nowhere; like Narcissus, the poet knows that should one turn away from this incessant self-contemplation, one would become no one. Consequently, the poet or author has to turn to personal literature, in which author, narrator, and hero-one's form, style, and subject-become mirrors contemplating and endlessly repeating each other. As a result, repetition becomes a structural or an organizational principle as well. Yet this literary solipsism, which reflects Narcissus's straits, is potentially self-destructive. And the death wish that informs Narcissus's experience informs as well the experience of the autobiographer, for the wish to return to an inorganic state is, in Freud's terms, the ultimate expression of the repetition compulsion. ${ }^{9}$ Moreover, in transforming life into destiny -in resurrecting the past as necessary - autobiographers in effect anticipate death, because they deny their continuing historical natures in order to repeat the past. Anticipating death, however, is a strategy for overcoming it, and the author plays dead, so to speak, only in order to be reborn. It is for this reason that each of the works to be considered-even as suicidal a work as The Education of Henry Adams-ends on a note of resurrection.

As event, then, autobiographical literature becomes a strategy for transcending one's historical essence. Seen as 
gesture, however, literature itself becomes part of history. If history is life becoming conscious of itself as time, as self-consciousness autobiographical literature creates this consciousness of time. In this way, such literature makes for history, not only for the individual but for the public or the culture that literature thereby helps to create. In the first place, narrative-or historically organized art in general-may be said to create a historical mode of perception, for when events are arranged in a temporal order they assume temporal relationships. Since language itself is a temporal medium, a narrative order may be seen as the refinement or the formalization of a general tendency of language itself. It is in poetry that the temporal nature of language is most fully exploited; just as sculpture and architecture create the sense of space, poetry may be said to create the very consciousness of time, for it is in poetry that time becomes functional. The fact that history began as narrative poetry attests to the idea that literature creates a historical mode of perception or experience. Furthermore, literature creates its occasion as history, for it is through literature that diverse phenomena occurring at a given time become a happening and constitute a moment. Thus the age congeals and becomes whole; the Transcendental age, the period of fin de siècle, and the Modern era, for example, are defined by the art that composed them.

Moreover, the work of art places itself in, and becomes part of, the history that it serves partly to create. The work of art is historical in a number of ways. First, we may apply Marcel Duchamp's view of art to works of literature. In his view, the work is not an object to which one reacts, but a "temporary center of energy which gives rise to psychic events." The work of art, then, is like an "irradiated substance," and only when its "charge" dies down does it begin to "last."10 In becoming historical, moreover, art escapes the Museum. As Harold Rosenberg suggests, although self-destructive works of art like happenings and earth works would appall a Duchamp, these developments are really extensions of Duchamp's idea of art as history. To a 
certain extent, self-destructive art represents a rebellion against both the possessiveness of the art public and the politics of the galleries; by escaping the Museum, however, art reveals its vulnerability, for the guise of fatedness is the protection that the Museum affords art. The idea that art en: oys a privileged position outside history derives from the concept of art as a necessary or fated activity. In renouncing these ideas of art, the artist becomes conscious of the arbitrariness of art. It is this awareness that troubles someone like James and leads him to construct, as it were, his own Museum - a superstructure that uses the art itself as its matériel. Frank O'Hara's poetry, which in some ways represents an extreme of autobiographical writing, likewise attests to a consciousness of the arbitrariness of art. In O'Hara's "Personism," each poem becomes the locus of an event - the point at which the inner and outer histories momentarily converge to define a truly historical self. Of course, such historical poetry may be abandoned to the confusion of history once its charge dies down - that is, after it has served as a "psychic event." This idea of the poem as historical event accounts for the unapologetically personal-not private-nature of O'Hara's poetry and explains his possibly cultivated carelessness with his poems, which he sometimes carried to the extent of not even keeping copies.

Second, just as the work of art has a private history, it also has a public history. The role of art in collective life is essentially cohesive, for the work creates its occasion as history at its inception and continues to make history each time it is read. According to Henri Focillon, the histories of the different expressions of collective life unfold at different speeds; ${ }^{11}$ for example, the rate of industrial change is not the same as the rate of change in the arts. A work of art, however, creates a moment or a "now" point which intersects all these continua. Using Walden as an example, we may regard it as a "now" point that represents a particular cross section of the continua of politics, economics, religion, American literature, and the humanizing or de- 
naturing of the American environment at the time of its writing. Since these continua have different rates of progress, Walden today represents a very different cross section than it did in 1854 , and it cannot be used to discover the particular cross section of 1854 . Walden as a "now" point - as pure form -is a continually changing set of contents, and in order to discover the particular configuration that it represented in 1854 , we would need independent knowledge of the period, which we would then try to match with the book. The only way that Walden can serve the purposes of a historian is by providing - at the time that it is under examination - a temporary center around which the accumulated historical facts may be organized. For whenever it is created or experienced, a work of art provides a stasis or a point in time at which the various continua that make up collective life are momentarily arrested in a particular relationship. It is in art, then, that experience becomes conscious, because the personal experience of the writer or reader can enter into a formal relationship with the collective experience.

Regarding a work as history also enables us to account for the changes of the work itself. Throughout its history a work accumulates perspectives and interpretations, takes on increasingly larger significance, and grows more and more multifarious. In other words, a work becomes the sum of its readings and contains, in a sense, not only numerous readers but all the years of its existence. Since a work is not a historical object or an antique but a living thing or, even, history itself, what it says to each reader and each age is its true nature, which-like all historical entitiesis continuously evolving. Whatever the author may have "really meant," then, is of specialized, even antiquarian, interest only.

Finally, a literary work has its own temporal structure, which embodies the life span of a consciousness. Since the form of a work is an internal temporal structure, all the changes that the work undergoes in the hands of different readers are changes within the limits of its first and last 
words, because there is no time before the work begins and no time after it ends. As Alain Robbe-Grillet claims about his "new novel," art is all "presence," for a novel is not a slice of time from a time continuum that exists outside the work but a complete time structure; when the work ends, therefore, time ends. ${ }^{12}$ The time span of a work of literature represents a total cycle of consciousness, and this cycle of consciousness - this birth, growth, and deathconstitutes its form.

Autobiography, however, is an open-ended genre, which posits a time before and after the work as part of the fiction itself. Yet when Thoreau, Whitman, James, and Adams transform autobiography into art, they compensate for the open-endedness of their form by completing their stories. For example, Thoreau isolates a span of years in Walden and makes them emblematic of a life cycle, complete with rebirth. More ambitious, Whitman encompasses a lifetime in "Song of Myself" and justifies his project by expanding Thoreau's natural life cycle into a mythic life cycle. James completes his form by writing his last Preface or the "story" of the story of the stories, and he also enacts the end of his life. Since his life is equated with his career, the writing of the Prefaces, which shows the career to be over, suggests that in a sense life, too, is over. Adams perfects this kind of suicidal maneuver in The Education of Henry Adams when he addresses us from beyond the grave, so to speak. On the other hand, Williams's and O'Hara's more impure conceptions of art enabled them to live with the open-endedness of their forms. For example, after bidding his reader a formal good-by at the end of Book 4 of Paterson with "This is the blast / the eternal close / . . the end," Williams refuses to let well enough alone and adds a fifth book to Paterson and even projects a sixth, simply because he is still living and thinking about the same things. Art is no more sacred to O'Hara; he ends "In Memory of My Feelings" with the announcement that it is time for the poem to end and for the time after the poem to begin. 
When literature is seen as ritual, the reader assumes her or his properly creative role. As event, autobiography calls out for an auditor who will complete or seal it. The "I" and the "you" whom the "I" addresses are both on stage; consequently, the work should not be seen as an object, because one cannot simply speak for oneself. Whom else one is speaking for depends upon which stage one is speaking from, what the props are, and who one's audience is. Sincerity, which is a significant issue in autobiographical writing, should therefore be conceived of dramatically as the aptness of the attitude struck for the particular purposes and the particular audience at hand. It is a matter of effects - a matter to be settled between the author and each reader. When the reader is also on stage, he or she must act and try to become the ideal audience that a particular work is addressing. In effect, the reader attempts to become the author's first reader - the author. As ritual experience, literature allows readers to participate-to act and to watch themselves act. This double perspective is built into the ritual experience, since one must view oneself both from within and from without one's immediate history. The perspective from infinity makes of the experience a ritual, while the historical perspective makes of the ritual a personal experience.

This double perspective in the ritual or dramatic experience of reading reflects the double perspective of autobiographical writing in general, for self-consciousness is common to both reading and writing. Both activities involve introspection and, at the same time, transcendence of the private self. Implicit in self-consciousness, then, is the very perspective by which it can be transcended, since one can escape being trapped in one's subjectivity only by being conscious of oneself as partly object. Thus, although selfconsciousness is, theoretically, infinitely regressive and therefore infinitely introspective, it also represents a continuous transcendence of introspection, for whatever consciousness is conscious of becomes thereby a part of history. Accordingly, self-consciousness, which defines autobiography, informs its double perspective, because the hero- 
author of autobiography is, at the same time, both in and out of history. This doubleness appears in each of the works under consideration. In Walden, for example, we see an opposition between the unselfconscious Narcissus-hero, who is not separated from his world, and the necessarily self-conscious-indeed, Promethean - author. Similarly, we find in "Song of Myself" a tension between the mythic bard-hero and the historical author. In the Prefaces, we watch James betray his self-consciousness in arguing for the unselfconscious and organic development of his works; his telltale final Preface, moreover, reveals a secondary self-consciousness-his sense of the arbitrariness of the entire project of the Prefaces. In The Education of Henry Adams, this doubleness takes the form of a conflict between the hero, who is a not altogether effective actor in history, and the author as observer.

A double perspective is basic to autobiography and informs even the oldest model of modern autobiography. Jean Starobinski remarks of Saint Augustine's Confessions that "the double address of the discourse-to God and to the human auditor-makes the truth discursive and the discourse true. Thus may be united, in a certain fashion, the instantaneousness of the confession offered to God and the sequential nature of the explanatory narrative offered to the human intelligence. And thereby are reconciled the edifying motivation and the transcendent finality of the confession."13 Substituting "consciousness" for "God," we arrive at the modern version of the essential doubleness of the self as both history and consciousness-as immanent and, at the same time, transcendent. Thus, since the self is both the narrative and the creator of the narrative, the very creation of the self in autobiography constitutes its transcendence. The " $\mathrm{I}$ " in autobiography, then, is not only past but present, both the observed and the observer, history and historian, hero and poet, form and life. And this peculiarity of autobiographical writing makes autobiography an essentially comic genre, because the authors consider their historical selves - indeed, history itself - from a comic perspective outside history. Walden, "Song of My- 
self," and The Education of Henry Adams, in each of which the hero-author is -in Whitman's words-"both in and out of the game" of history, can all be seen as comic works. Even James's Prefaces contain a comic perspective, although James minimizes this doubleness by attempting to formalize the very history of his forms. In fact, repetition -which is the essence of the autobiographical impulsenecessarily creates a double perspective, for in repeating history one is of necessity both in and out of history. The twentieth-century poets Williams and O'Hara consciously exploit this double perspective. Williams juxtaposes "poetic" pieces, found prose, and eyewitness reporting in Paterson, and O'Hara constantly reminds us in his poems that he is writing poetry. In Williams and O'Hara, then, art is seen from the perspective of history, and the hero as artist is seen from the perspective of the person in history.

Given this doubleness of autobiographical writing, I attempt to consider these works both from the inside or as history and from the outside or as form. Each chapter focuses primarily on the aspect of autobiographical writing that is most prominent in the work at hand. Although there is traffic between the chapters, it remains for each reader to make the connections between them as explicit as she or he may require. The first chapter deals mainly with the necessary narcissism of autobiography and its economies. Equally central to all the works that are studied is the process by which history becomes myth, and the second chapter is organized around an examination of this process. I then proceed to a discussion of self-consciousness, retrospection, and narrative, which structure each of the works considered. The fourth chapter emphasizes the double perspective of comedy, and the final chapter studies the formal innovativeness of autobiographical writing. Thus each work is treated as a mirror which may reflect other works. I am interested in these ideas to the extent that they enable us to discuss a literary work as a total experience, as an event, or as a locus for the interaction not simply of history and form but of author, reader, and even critic. 